\title{
Fruit Textural Characteristics of 23 Plum (Prunus salicina Lindl) Cultivars: Evaluation and Cluster Analysis
}

\author{
Xia Qiu, Haonan Zhang, Huiyi Zhang, Changwen Duan, Bo Xiong, \\ and Zhihui Wang \\ College of Horticulture, Sichuan Agricultural University, Chengdu, 611130, \\ Sichuan, China
}

Additional index words. categories, fruit quality, germplasm resources, stone fruits, sensory characteristics

\begin{abstract}
Fruit textural characteristics can affect the storage, transportation, and processing of plum (Prunus salicina Lindl) in commercial production. We analyzed 23 plum cultivars with marked differences in fruit traits. Basic physicochemical indicators and textural characteristics of the fruits were determined using puncture testing and texture profile analysis. Furthermore, through the combined application of cluster analysis and principal component analysis, the indexes were simplified to three relatively independent dimensions, comprehensively reflecting the hardness, size, and flexibility of plum fruit. Our results show a high positive correlation among textural characteristics such as hardness, springiness, gumminess, and chewiness, whereas toughness and brittleness were negatively correlated. In addition, physicochemical properties were correlated to the texture traits. The weight and size of the plum fruit were related to hardness, adhesiveness, and chewiness. The soluble solids and water content contributed to the hardness, cohesiveness, and resistance to chewing. Cluster analysis revealed three distinct clusters: Cluster I represented by 'Meiguihong' with high hardness and a chewable texture; Cluster II represented by 'Siyuecui', 'Cuimi', and 'Qingcui' with a hard and brittle texture; and Cluster III represented by 'Jinmi', 'Taoli', and 'Oishiwase' with a soft and tough texture. The results of this study provide a significant theoretical foundation for quality evaluation, and classification of plum fruit characteristics, thus providing insights for further breeding of plum varieties.
\end{abstract}

Plum (Prunus salicina) is one of the most important stone fruits cultivated worldwide $(\mathrm{Li}$ et al., 2015). Plum fruits are rich in fiber and polyphenolics (Kim et al., 2003; Stacewicz-Sapuntzakis et al., 2001) and are becoming increasingly popular with consumers due to their attractive appearance and unique flavor (Cuevas et al., 2015). According to the Food and Agriculture Organization Corporate Statistical Database, China's plum cultivation area in 2019 was 2.11 million $\mathrm{hm}^{2}(77.3 \%$ of the world's total), and the yield was 7 million $t$ (55.6\% of the world's total), making China the major plum production country in the world (Food and Agricultural Organization, 2020). Plum germplasm resources are rich and widely distributed in China (Zhang and Zhou, 1998). The formation of different qualities is determined by a series of physiological and

Received for publication 12 Mar. 2021. Accepted for publication 22 Apr. 2021.

Published online 8 June 2021.

We acknowledge financial support from the Science and Technology Department of Sichuan Province (grant no. 2017CC0077 to Z.W.).

Z.W. is the corresponding author. E-mail: wangzhihui318@126.com.

This is an open access article distributed under the CC BY-NC-ND license (https://creativecommons. org/licenses/by-nc-nd/4.0/). biochemical changes during fruit ripening (Bouzayen et al., 2010). These changes include the transformation of fruit color, conversion of sugars and acids, synthesis of volatile secondary metabolites, and fruit softening (Farcuh et al., 2018; Vlaic et al., 2018). Plum germplasm resources show considerable variability in all these characteristics related to fruit ripening, which highly affects their commercial acceptability. Current research on plum fruits mainly focuses on organic acids, soluble sugars, and secondary metabolism (Jiang et al., 2019; Liaudanskas et al., 2020; Usenik et al., 2008), whereas the sensory characteristics have not been thoroughly analyzed, and the textural properties of plums have been rarely reported. Previous studies on the preference of horticultural products have repeatedly demonstrated that texture attributes are very important in preference models (Causse et al., 2010; Vigneau et al., 2014). Moreover, studies have shown that consumers were more sensitive to subtle changes in texture than flavor (Beaulieu et al., 2010).

Fruit texture is not only an essential driver of consumer preference but also an important attribute that reflects its internal structural characteristics (Schmitz et al., 2013). During fruit ripening, the textural characteristics are mainly affected by traits related to softening, such as changes in cuticle architecture, cell enlargement, and the composition of the cell wall polysaccharide (Ayour et al., 2021). Although fruit moderate softening is desirable from the consumer's perspective, it dramatically limits the postharvest storage, shelf life, transportation, and processing of horticultural products (Nybom et al., 2020; Wong et al., 2020). Thus, texture traits are important in assessing the commercial quality of plum fruit (Szczesniak, 2010). However, because of the numerous plum germplasm resources and diverse aspects, there are currently no suitable criteria for evaluating plum texture. Therefore, a study of the textural characteristics of different plum cultivars is needed to establish a set of effective methods for the comprehensive evaluation of plum fruit quality. This requires an exploration of the key factors that constitute the textural characteristics necessary to improving texture quality.

Although the texture is important, it is difficult to evaluate accurately. The texture was defined by Bourne (2002) as a set of physical characteristics mainly related to the structural elements of food, which are primarily perceived by the sensation of touch. The assessment of fruit texture includes two approaches: sensory evaluation and instrument measures. For a long time, fruit texture was assessed and scored by trained judges using sensory evaluation (Harker et al., 2002), which lacks scientific judgment standards and objectivity (Chen et al., 2015). Recently, the development of a texture analyzer has facilitated the instrumental evaluation of fruit texture. The texture analyzer simulates chewing by human teeth, thereby enabling the analysis of food texture characteristics, which has a higher sensitivity and objectivity than sensory evaluation (Contador et al., 2015; Ghnimi et al., 2018). Among the measurement modes of texture analyzer, texture profile analysis (TPA) and puncture testing (PT) are widely used for assessing horticultural products. In TPA, the pressure of the probe on the sample as well as other relevant texture parameters are obtained by compressing the sample twice (Jubb, 1982). The result is related to the shape and size of the sample, the number of test repetitions, and the setting of parameters (Canet et al., 2007). Puncture testing can sensitively and efficiently measure the texture properties of specific parts of a sample without being affected by the shape and size, as well as accurately obtaining multiple indexes (Zhou et al., 2020). To date, a texture analyzer has been used to evaluate the diversity of melon textures (Farcuh et al., 2020), determine the differences in the texture of jackfruit at different stages of maturity (Rana et al., 2018), analyze the changes in apple brittleness during storage (Chang et al., 2018), and investigate the relationship between the dry matter content and texture properties of kiwifruit (Nardozza et al., 2011).

We used two texture detection methods, TPA and PT, to measure the textural characteristics of 23 plum cultivars and analyze the correlation between textural characteristics and basic physicochemical indicators. Furthermore, we used cluster analysis to classify different plum cultivars according to their textural characteristics and combined this 
with principal component analysis (PCA) to extract their main factors. This enabled us to construct a comprehensive score model to achieve a comprehensive evaluation of plum fruit texture quality. Our results provide a theoretical basis for improving the quality evaluation system of plum fruit and the selection of high-quality plum cultivars.

\section{Materials and Methods}

Experimental materials. Twenty-three plum (Prunus salicina) cultivars with distinct differences in fruit texture were sampled at the maturity stage. The test materials included 'Oishiwase', 'Xinfan', 'Taoli', 'Yanzhi', 'Zaiyang', 'Jiuqian', 'Siyuecui', 'Wuyuecui', 'Fengtang', 'Bingtang', 'Gulf-ruby', 'Friar', 'Jixue', 'Dabai', 'Cuimi', 'Meiguihong', 'Yuhuang', 'Kongxin', 'Furong', 'Jinmi', 'Qingcui', 'Yinhong', and 'Cuihong', in order of the timing of fruit maturation. The experimental materials were planted in a plum cultivation demonstration orchard in Dayi, Sichuan, China. All the test plants were managed following a standard procedure, referencing the Technical Regulation for the Cultivation of Plum (LY/T 2826-2017). For fruit sampling, we selected nine trees of each cultivar (three replicates of three trees) and collected a total of 90 fruit per cultivar from these trees. We selected fruit of the same size, with a similar number of growth days that were disease-free and without pest or mechanical damage.

Determination of basic physicochemical indexes. Single fruit weight was measured using an electronic balance (AL204; Mettler Toledo, Greifensee, Switzerland). Ten fruits were cut into pieces, and $10 \mathrm{~g}$ of chopped flesh was weighed and dried to a constant weight to determine the water content, with three repeats for each cultivar. Transverse,

Table 1. Parameter definition and calculation of puncture testing and texture profile analysis. The texture parameters in the table are defined by reference to Dong et al. (2020) and TMS-PRO operating guidelines.

\begin{tabular}{|c|c|c|}
\hline Parameters & Definition & Units \\
\hline Peel hardness & $\begin{array}{l}\text { The force at the maximum peak during the } \\
\text { puncture testing }\end{array}$ & $\mathrm{N}$ \\
\hline Flesh hardness & The force felt by the probe when the puncture depth reaches $25 \%$ & $\mathrm{~N}$ \\
\hline Brittleness & $\begin{array}{l}\text { The maximum modulus of puncture: the slope between the initial } \\
\text { point of puncture and the point at which maximum force is } \\
\text { reached during the puncture process }\end{array}$ & $\mathrm{N} \cdot \mathrm{mm}^{-1}$ \\
\hline Toughness & $\begin{array}{l}\text { The displacement at the maximum hardness: the displacement at } \\
\text { the maximum force during the puncture process }\end{array}$ & $\mathrm{mm}$ \\
\hline Hardness 1 & Maximum strength peak for the first extrusion cycle & $\mathrm{N}$ \\
\hline Adhesiveness & $\begin{array}{l}\text { The area of the curve in the negative direction of the coordinate axis } \\
\text { between two extrusion cycles }\end{array}$ & $\mathrm{mj}$ \\
\hline Cohesiveness & $\begin{array}{l}\text { The ratio of the positive peak area of the second extrusion cycle to the } \\
\text { positive peak area of the first extrusion cycle }\end{array}$ & Ratio \\
\hline Springiness & $\begin{array}{l}\text { The ratio of the height of the second compression to that of the first } \\
\text { compression }\end{array}$ & $\mathrm{mm}$ \\
\hline Gumminess & Hardness $1 \times$ cohesiveness & $\mathrm{N}$ \\
\hline Chewiness & Hardness $1 \times$ cohesiveness $\times$ springiness & $\mathrm{mj}$ \\
\hline
\end{tabular}

lateral, and vertical diameters were measured using an electronic Vernier caliper. Total soluble solids (TSS) in the juice from the equatorial part of the fruit were determined using a handheld refractometer (PAL-1; ATAGO Co., Ltd., Tokyo, Japan) (Famiani et al., 2012). All indexes were repeated three times.

Puncture testing. The PT was carried out following Farcuh et al. (2020), with modifications, using a texture measurement system (TMS-Pro; FTC, Sterling, VA) and a cylindrical probe with a 5-mm diameter. We set the parameters as follows: the test speed was $40 \mathrm{~mm} \cdot \mathrm{min}^{-1}$, the initial force was $0.75 \mathrm{~N}$, and the puncture depth was $25 \%$ of the average value of the transverse and lateral diameter. The puncture depth was obtained from the preliminary experiment, which ensured that the test would not be ended due to the touching of the fruit stone of any plum cultivar during the experiment. The PT was carried out on the equatorial surface of the fruit, avoiding the suture line. Each cultivar was tested 30 times, and the peel hardness, flesh hardness, toughness, and brittleness were recorded (Table 1).

Texture profile analysis. The TPA was carried out following Dong (2020), with modifications, using a texture measurement system (TMS-Pro) and a disk-shaped probe with a 50-mm diameter. The parameter settings were as follows: the test speed was $40 \mathrm{~mm} \cdot \mathrm{min}^{-1}$, the initial force was $0.75 \mathrm{~N}$, and the extrusion deformation was $50 \%$. The extrusion deformation was obtained from a preliminary experiment, which tested the maximum value that could be set under the conditions of not compressing the fruit stone of all plum cultivars. The suture line of the plum fruit was facing down during TPA. Each cultivar was tested nine times, and hardness 1 , adhesiveness, cohesiveness, springiness, gumminess, and chewiness were recorded (Table 1).

Table 2. Comparison of basic physicochemical characters of 23 plum cultivars. Each value shows in mean \pm SE $(\mathrm{n}=3$ ). Different letters indicate statistical differences $(P \leq 0.05)$, and the least significant difference was used for mean separation.

\begin{tabular}{|c|c|c|c|c|c|c|}
\hline Variety & Fruit wt (g) & Transverse diam $(\mathrm{cm})$ & Lateral diam $(\mathrm{cm})$ & Vertical diam $(\mathrm{cm})$ & Total soluble solids (\%) & Water content $(\%)$ \\
\hline Oishiwase & $43.18 \pm 0.58$ ef & $4.25 \pm 0.03 \mathrm{e}$ & $4.20 \pm 0.02 \mathrm{f}$ & $4.69 \pm 0.02 \mathrm{c}$ & $10.40 \pm 0.06 \mathrm{ij}$ & $90.15 \pm 0.23 \mathrm{abc}$ \\
\hline Xinfan & $33.43 \pm 0.49 \mathrm{~h}$ & $4.04 \pm 0.04 \mathrm{~g}$ & $3.76 \pm 0.04$ hij & $3.71 \pm 0.09 \mathrm{ij}$ & $13.20 \pm 0.12 \mathrm{bcd}$ & $85.37 \pm 0.54 \mathrm{kl}$ \\
\hline Taoli & $45.63 \pm 0.66 \mathrm{e}$ & $4.41 \pm 0.05 \mathrm{e}^{\circ}$ & $4.08 \pm 0.11 \mathrm{f}$ & $4.53 \pm 0.06 \mathrm{~cd}$ & $10.40 \pm 0.30 \mathrm{ij}$ & $90.72 \pm 0.16 \mathrm{ab}$ \\
\hline Yanzhi & $22.39 \pm 0.48 \mathrm{k}$ & $3.43 \pm 0.04 \mathrm{~lm}$ & $3.30 \pm 0.08 \mathrm{k}$ & $3.07 \pm 0.041$ & $9.87 \pm 0.26 \mathrm{j}$ & $90.69 \pm 0.17 \mathrm{ab}$ \\
\hline Zaiyang & $21.07 \pm 0.46 \mathrm{k}$ & $3.38 \pm 0.01 \mathrm{~m}$ & $3.28 \pm 0.01 \mathrm{kl}$ & $3.42 \pm 0.04 \mathrm{k}$ & $12.17 \pm 0.41 \mathrm{ef}$ & $87.94 \pm 0.32$ efgh \\
\hline Jiuqian & $9.80 \pm 0.211$ & $2.92 \pm 0.01 \mathrm{n}$ & $2.67 \pm 0.05 \mathrm{~m}$ & $2.56 \pm 0.06 \mathrm{~m}$ & $13.53 \pm 0.30 \mathrm{abc}$ & $87.13 \pm 0.52$ fghij \\
\hline Siyuecui & $37.25 \pm 0.54 \mathrm{~g}$ & $4.26 \pm 0.10 \mathrm{e}$ & $4.02 \pm 0.07 \mathrm{fg}$ & $3.79 \pm 0.06 \mathrm{hi}$ & $9.63 \pm 0.20 \mathrm{j}$ & $90.74 \pm 0.15 \mathrm{ab}$ \\
\hline Wuyuecui & $27.48 \pm 0.59 \mathrm{j}$ & $3.64 \pm 0.06 \mathrm{ijk}$ & $3.56 \pm 0.05 \mathrm{j}$ & $3.54 \pm 0.01 \mathrm{jk}$ & $14.30 \pm 0.35 \mathrm{a}$ & $85.69 \pm 0.44 \mathrm{jkl}$ \\
\hline Fengtang & $51.44 \pm 0.85 \mathrm{~d}$ & $4.76 \pm 0.01 \mathrm{~d}$ & $4.50 \pm 0.03 \mathrm{e}$ & $4.38 \pm 0.08 \mathrm{de}$ & $11.70 \pm 0.31 \mathrm{fgh}$ & $87.30 \pm 0.12$ efghi \\
\hline Bingtang & $54.71 \pm 0.92 \mathrm{c}$ & $5.37 \pm 0.05 \mathrm{ab}$ & $4.98 \pm 0.09 \mathrm{~cd}$ & $4.21 \pm 0.10 \mathrm{ef}$ & $13.87 \pm 0.37 \mathrm{ab}$ & $89.47 \pm 0.33$ bcd \\
\hline Gulf-ruby & $63.63 \pm 1.20 \mathrm{~b}$ & $5.22 \pm 0.14 \mathrm{bc}$ & $5.17 \pm 0.08 \mathrm{bc}$ & $3.54 \pm 0.04 \mathrm{jk}$ & $13.60 \pm 0.21 \mathrm{abc}$ & $88.72 \pm 0.47 \mathrm{cde}$ \\
\hline Friar & $54.90 \pm 0.40 \mathrm{c}$ & $5.12 \pm 0.05 \mathrm{c}$ & $4.92 \pm 0.09 \mathrm{~d}$ & $4.44 \pm 0.12 \mathrm{~d}$ & $11.07 \pm 0.19 \mathrm{hi}$ & $86.84 \pm 0.56$ ghijk \\
\hline Jixue & $63.70 \pm 0.56 b$ & $5.47 \pm 0.04 \mathrm{a}$ & $5.20 \pm 0.05 \mathrm{~b}$ & $5.11 \pm 0.03 \mathrm{~b}$ & $13.83 \pm 0.26 \mathrm{ab}$ & $87.43 \pm 0.52$ efghi \\
\hline Dabai & $28.10 \pm 0.72 \mathrm{j}$ & $3.57 \pm 0.01 \mathrm{klm}$ & $3.07 \pm 0.061$ & $3.00 \pm 0.061$ & $12.07 \pm 0.32 \mathrm{efg}$ & $86.40 \pm 0.32 \mathrm{ijk}$ \\
\hline Cuimi & $29.55 \pm 0.29 \mathrm{ij}$ & $3.90 \pm 0.03 \mathrm{gh}$ & $3.82 \pm 0.06 \mathrm{gh}$ & $3.46 \pm 0.07 \mathrm{k}$ & $12.47 \pm 0.09 \mathrm{def}$ & $88.37 \pm 0.38 \mathrm{def}$ \\
\hline Meiguihong & $82.27 \pm 1.75 \mathrm{a}$ & $5.54 \pm 0.06 \mathrm{a}$ & $5.50 \pm 0.05 \mathrm{a}$ & $5.45 \pm 0.08 \mathrm{a}$ & $12.23 \pm 0.23 \mathrm{ef}$ & $88.07 \pm 0.63 \mathrm{defg}$ \\
\hline Yuhuang & $32.18 \pm 0.55 \mathrm{~h}$ & $3.83 \pm 0.03 \mathrm{hi}$ & $3.60 \pm 0.08 \mathrm{ij}$ & $3.84 \pm 0.03 \mathrm{ghi}$ & $13.37 \pm 0.35 \mathrm{bc}$ & $86.48 \pm 0.32$ hijk \\
\hline Kongxin & $31.55 \pm 0.64 \mathrm{hi}$ & $4.24 \pm 0.04 \mathrm{ef}$ & $3.80 \pm 0.01 \mathrm{hi}$ & $4.05 \pm 0.03 \mathrm{fg}$ & $11.27 \pm 0.15 \mathrm{gh}$ & $88.28 \pm 0.40 \mathrm{defg}$ \\
\hline Furong & $33.63 \pm 0.96 \mathrm{~h}$ & $4.28 \pm 0.03 \mathrm{e}$ & $4.05 \pm 0.01 \mathrm{f}$ & $4.38 \pm 0.02 \mathrm{de}$ & $11.10 \pm 0.15 \mathrm{hi}$ & $86.41 \pm 0.62 \mathrm{ijk}$ \\
\hline Jinmi & $41.13 \pm 0.93 \mathrm{f}$ & $4.38 \pm 0.08 \mathrm{e}$ & $4.05 \pm 0.03 \mathrm{f}$ & $3.97 \pm 0.06 \mathrm{gh}$ & $11.63 \pm 0.03 \mathrm{fgh}$ & $91.29 \pm 0.61 \mathrm{a}$ \\
\hline Qingcui & $28.30 \pm 0.45 \mathrm{j}$ & $3.77 \pm 0.06$ hij & $3.55 \pm 0.08 \mathrm{j}$ & $3.51 \pm 0.03 \mathrm{jk}$ & $11.87 \pm 0.12 \mathrm{fgh}$ & $87.27 \pm 0.22$ efghi \\
\hline Yinhong & $31.40 \pm 0.49 \mathrm{hi}$ & $4.05 \pm 0.02 \mathrm{fg}$ & $3.73 \pm 0.01 \mathrm{hij}$ & $3.53 \pm 0.06 \mathrm{jk}$ & $13.97 \pm 0.09 \mathrm{ab}$ & $85.45 \pm 0.44 \mathrm{kl}$ \\
\hline Cuihong & $23.65 \pm 0.16 \mathrm{k}$ & $3.60 \pm 0.04 \mathrm{jkl}$ & $3.33 \pm 0.04 \mathrm{k}$ & $3.20 \pm 0.031$ & $12.77 \pm 0.09 \mathrm{cde}$ & $84.86 \pm 0.371$ \\
\hline Mean & 38.71 & 4.24 & 4.01 & 3.95 & 12.19 & 87.87 \\
\hline $\mathrm{CV}$ & 0.43 & 0.17 & 0.18 & 0.19 & 0.11 & 0.02 \\
\hline
\end{tabular}



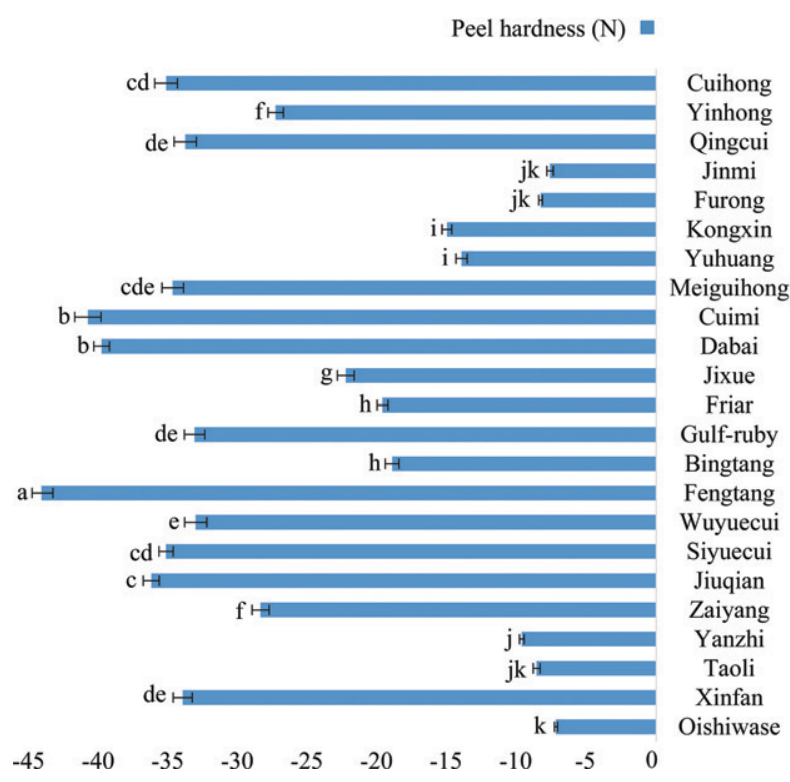

Flesh hardness $(\mathrm{N})$

Fig. 1. Comparison of peel hardness and flesh hardness of 23 plum cultivars. Each value shows mean \pm SE $(n=3)$. Different letters indicate statistical differences $(P \leq 0.05)$, and the least significant difference was used for mean separation.

Statistical analysis. All experimental data were expressed as the mean \pm SD of triplicate analyses. The statistical significance test, PCA, and cluster analysis were performed using SPSS 23.0 (IBM, Armonk, NY) and Origin 2021 (OriginLab, Northampton, MA). A statistical significance $(P \leq 0.05)$ of the various culrange tests, and the least significant difference was used for mean separation. Figures were generated using Excel 2016 (Microsoft, Redmond, WA), Origin 2021, and Adobe Illustrator 2020 (Adobe, San Jose, CA).

\section{Results}

Physicochemical properties. The physicochemical properties measured here showed tivars was assessed using Duncan's multiple

significant differences among the 23 cultivars (Table 2). The coefficient of variation of single fruit weight, water content, and other indexes were $0.43,0.02$, and $0.11-0.19$, respectively, indicating a relatively large difference in fruit weight among different cultivars but a relatively small difference in water content.

The fruit weight of 'Meiguihong' (82.27 g) was significantly higher than that of the other cultivars, followed by 'Jixue' and 'Gulf-ruby', whereas 'Jiuqian' had the lowest single fruit weight (9.80 g). 'Meiguihong' had the highest transverse $(5.54 \mathrm{~cm})$, lateral $(5.50 \mathrm{~cm})$, and vertical $(5.45 \mathrm{~cm})$ fruit diameters, whereas the corresponding values for 'Jiuqian' fruit were only $2.92,2.67$, and $2.56 \mathrm{~cm}$, respectively.

The TSS is an important index for determining fruit quality. 'Wuyuecui' had the highest

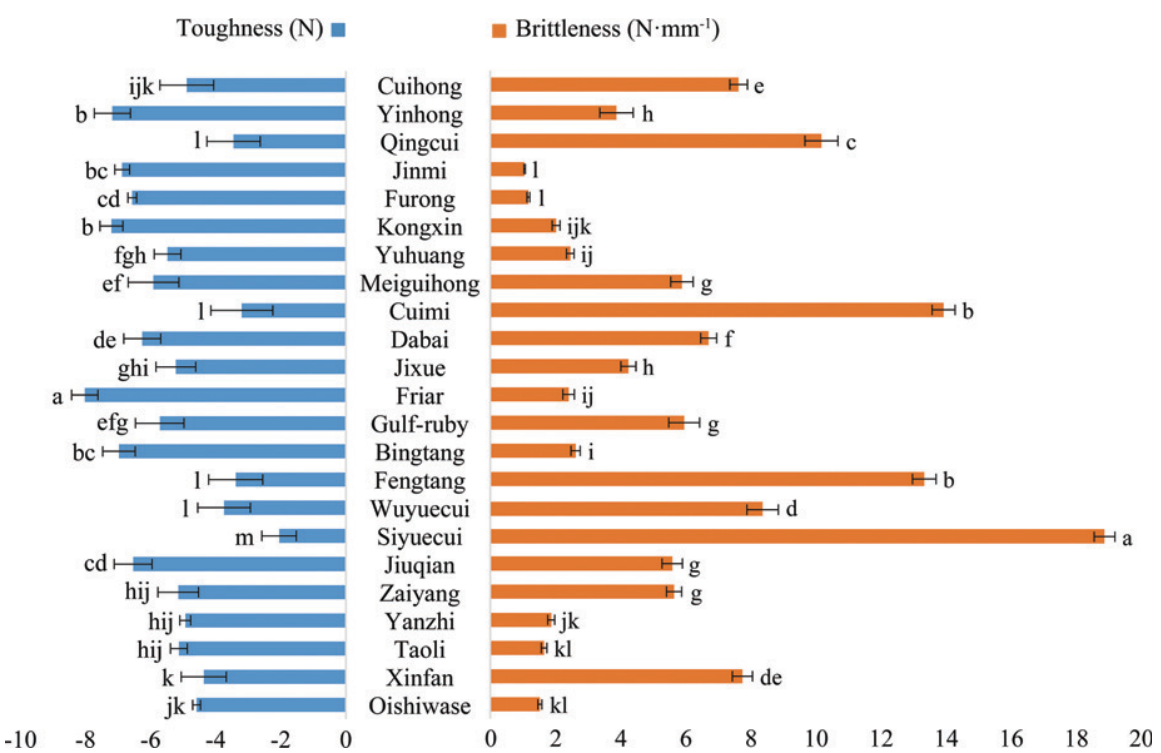

Fig. 2. Comparison of toughness and brittleness of 23 plum cultivars. Each value shows mean \pm SE $(n=$ 3). Different letters indicate statistical differences $(P \leq 0.05)$, and the least significant difference was used for mean separation.
TSS (14.30\%), followed by 'Yinhong' and 'Bingtang', whereas 'Yanzhi' (9.87\%) and 'Siyuecui' $(9.63 \%)$ had the lowest TSS values. The water content was relatively similar among the plum cultivars, varying only by $6.43 \%$ from lowest to highest. The water content was the highest in 'Jinmi', 'Siyuecui', and 'Taoli' fruits and the lowest in 'Yinhong', 'Xinfan', and 'Cuihong' fruits.

Textural characteristics determined by puncture testing. The main PT characteristics showed significant differences among the plum cultivars. The average peel hardness was 25.97 N. Fruits of 'Fengtang' had the hardest peels $(44.89 \mathrm{~N})$, followed by 'Cuimi' $(41.50 \mathrm{~N})$ and 'Dabai' $(40.50 \mathrm{~N})$, whereas 'Oishiwase' fruits had the softest peels $(7.34 \mathrm{~N})$. There was less variation in flesh hardness than peel hardness among the cultivars (Fig. 1). 'Yanzhi', 'Taoli', 'Oishiwase', 'Furong', and 'Jinmi' had the lowest peel hardness $(<10 \mathrm{~N})$ and flesh hardness $(<3 \mathrm{~N})$.

The average fruit toughness and brittleness among the 23 cultivars were $5.35 \mathrm{~mm}$ and 5.86 $\mathrm{N} \cdot \mathrm{mm}^{-1}$, respectively, and there was less variation in toughness $(5.98 \mathrm{~mm})$ than in brittleness $\left(17.8 \mathrm{~N} \cdot \mathrm{mm}^{-1}\right)$ (Fig. 2). The 'Friar' fruits were significantly tougher $(8.03 \mathrm{~mm})$ than those produced by the other cultivars, followed by 'Kongxin' and 'Yinhong'. In contrast, 'Siyuecui' (2.05 mm), 'Cuimi' (3.20 mm), and 'Fengtang' (3.39 mm) fruits had low toughness; however, these three cultivars had the highest brittleness values, at $18.85,13.93$, and 13.34 $\mathrm{N} \cdot \mathrm{mm}^{-1}$, respectively, suggesting there may be a specific negative correlation between toughness and brittleness.

Textural characteristics determined from texture profile analysis. The main textural characteristics determined by TPA were significantly different among the 23 cultivars. The results showed that hardness 1 varied between 29.62 and $401.55 \mathrm{~N}$, adhesiveness between 0.2 and $2.17 \mathrm{mj}$, cohesiveness between 0.071 and 2.17 , springiness between 4.72 and $13.12 \mathrm{~mm}$, gumminess between 2.61 and $50.35 \mathrm{~N}$, and chewiness between 13.03 and $568.10 \mathrm{mj}$ (Fig. 3).

Hardness, gumminess, and chewiness reflect the overall compactness and firmness of the fruit. The average hardness 1 of the 23 plum cultivars was $170.70 \mathrm{~N}$. The 'Jixue' (401.55 N), 'Meiguihong' (373.55 N), and 'Gulf-ruby' $(275.80 \mathrm{~N})$ had the highest hardness 1 , gumminess, and chewiness values, indicating a possible relationship between them. In contrast, 'Jinmi', 'Furong', and 'Taoli' showed the lowest values in these three characteristics.

Adhesiveness represents the energy required to overcome the force of attraction between the surface of the fruit and the tooth. It was highest in 'Bingtang' and 'Jinmi' fruit, at 2.17 and 2.05 $\mathrm{mj}$, respectively, and was the lowest in 'Jiuqian' and 'Cuimi' fruit. Cohesiveness reflects the size of the cohesive force between the cells of the fruit tissue. It was the highest in the 'Kongxin' and 'Gulf-ruby' fruit at 0.160 and 0.158 , respectively, whereas it presented the lowest values in the fruit of 'Oishiwase' and 'Taoli'. Springiness indicates the ability of the fruit to recover from compression. It was the highest in the fruit of 

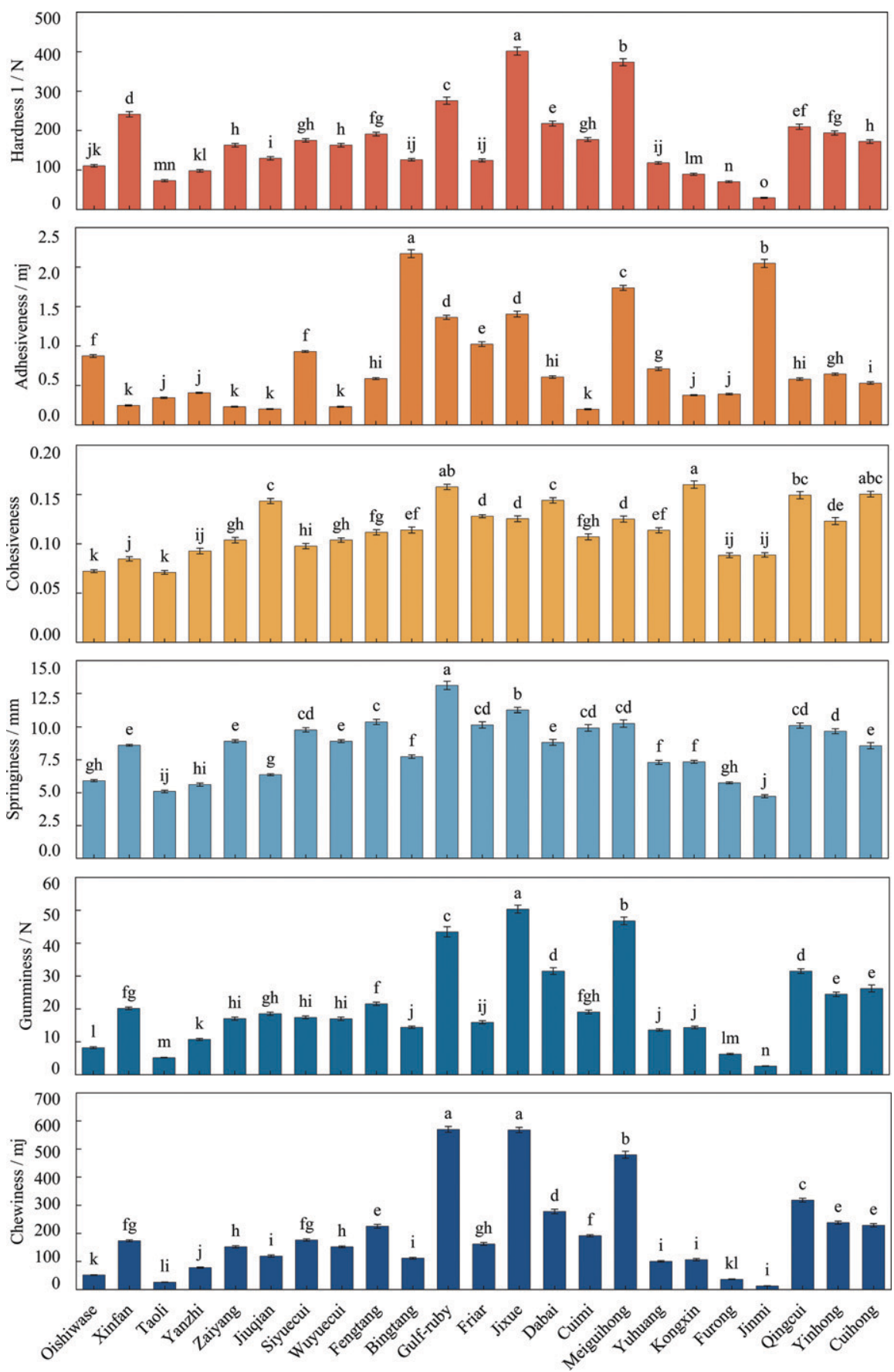

Fig. 3. Comparison of texture profile analysis (TPA) parameters of 23 plum cultivars. Each value shows in mean $\pm \operatorname{SE}(n=3)$. Different letters indicate statistical differences $(P \leq 0.05)$, and the least significant difference was used for mean separation.

'Gulf-ruby' and 'Jixue' (13.12 and $11.25 \mathrm{~mm}$, respectively) and the lowest in the 'Taoli' and 'Jinmi' fruit.

Correlation analysis. Representative textural characteristics determined by PT and TPA, and physicochemical indicators were selected for correlation analysis. The results showed the existence of complex correlations among the indicators (Fig. 4).

The correlation matrices of peel hardness and flesh hardness determined by PT presented similar values, with a correlation of 0.87 . These textural characteristics had significant positive correlations with brittleness, hardness 1, springiness, gumminess, and chewiness, but a content. This was information that the PT mode did not reveal. Furthermore, adhesiveness was strongly correlated only with quality and size indicators but not with other texture indicators. The other four characteristics determined by TPA, such as cohesiveness, springiness, gumminess, and chewiness, exhibited similar information. These findings suggest an overlap in the information represented by TPA.

Moreover, our findings showed that the quality and size of plum fruit greatly influence the hardness, adhesiveness, and chewiness. Thus, the soluble solids and water content play a key role in determining the fruit's peel firmness, cohesiveness, and chewing characteristics.

Cluster analysis. On the basis of the 16 indicators determined in this experiment, after normalization, a systematic cluster analysis of texture characteristics of the 23 plum cultivars was performed. The results showed that with a Euclidean distance of 30, all the cultivars were grouped into three distinct clusters (Fig. 5). Cluster I contained three cultivars: Meiguihong, Jixue, and Gulf-ruby. Cluster II comprised 11 cultivars, including Qingcui, Cuimi, and Fengtang. Nine cultivars formed Cluster III, including Friar, Bintang, and Kongxin (Fig. 5).

Different indexes were associated with each of the three clusters, especially fruit weight, brittleness, hardness 1, gumminess, and chewiness (Supplemental Table 1). Cluster I was associated with the largest fruit size and the highest TSS. The hardness and chewiness of Cluster I fruit were also relatively high, with average values of $350.30 \mathrm{~N}$ and $539.36 \mathrm{mj}$, respectively. Cluster II presented a small fruit size and relatively low water content. However, the peel hardness, flesh hardness, and brittleness of Cluster II were relatively high, with average values of 35.88 , 13.37 , and $9.26 \mathrm{~N} \cdot \mathrm{mm}^{-1}$, respectively. Cluster III fruit showed a medium fruit shape, a low soluble solids content, and a high-water content. This cluster was also associated with the highest toughness, with an average of $6.20 \mathrm{~mm}$. In addition, except for toughness and adhesiveness, the other eight texture-related indicators were low in Cluster III.

Principal component analysis. We conducted dimension-reduced processing on the 16 individual indicators through PCA. The first principal component (PC1) accounted for $39.1 \%$ of the total change, $\mathrm{PC} 2$ accounted for $30.0 \%$, PC3 accounted for $13.3 \%$, and the cumulative contribution rate of these three principal components was $82.4 \%$ (Fig. 6). It reflected most of the information provided by the initial indicators.

To better explain the relationship between the textural characteristics and the component factors, the extracted principal component factors were rotated, and the load values were obtained. In the PC1 dimension, chewiness, gumminess, springiness, hardness 1 , and peel hardness were mainly loaded, reflecting the hardness and chewing texture of non-plums (Supplemental Table 2). In the PC2 dimension, vertical diameter, transverse diameter, fruit weight, lateral diameter, and adhesiveness were mainly loaded, reflecting the size and adhesiveness of different plum cultivars 


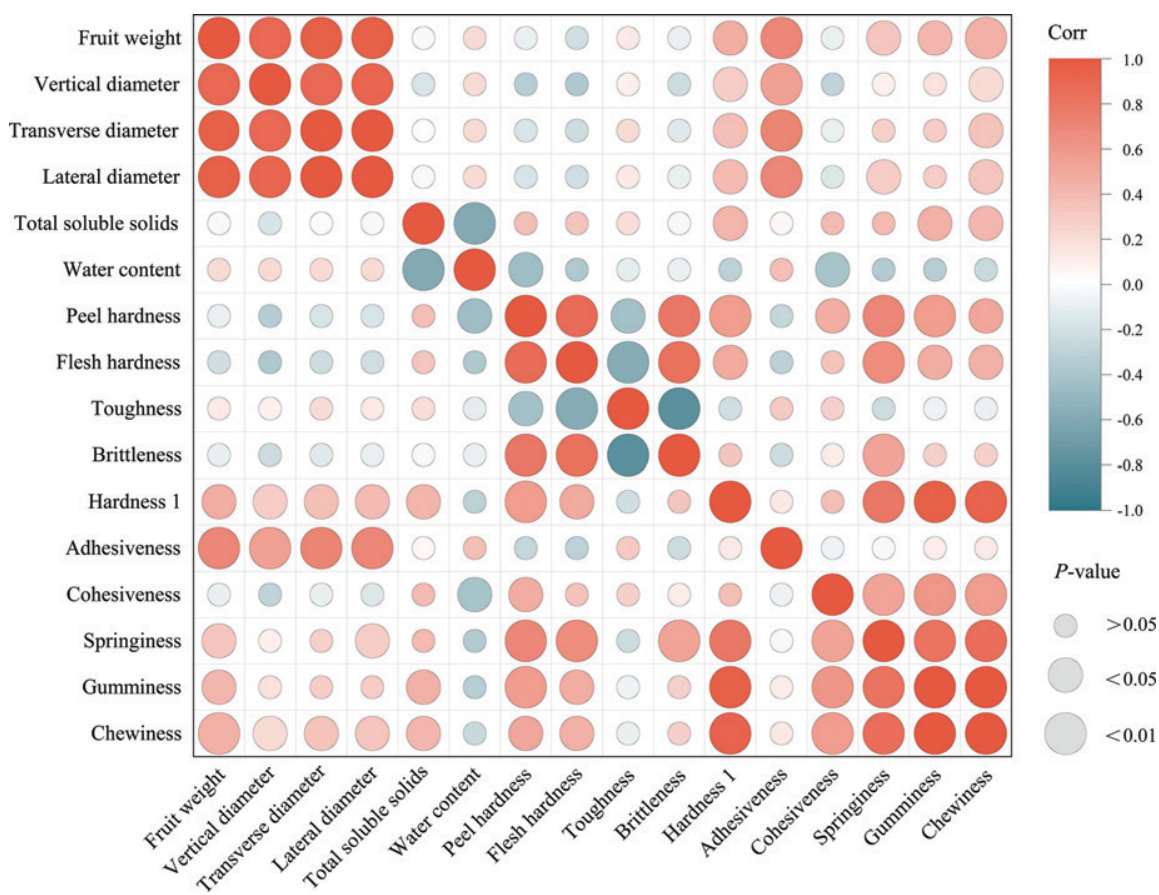

Fig. 4. Pearson correlation matrix heat map. The different colors represent Pearson correlation coefficients, and the diverse circle sizes represent $P$ value.

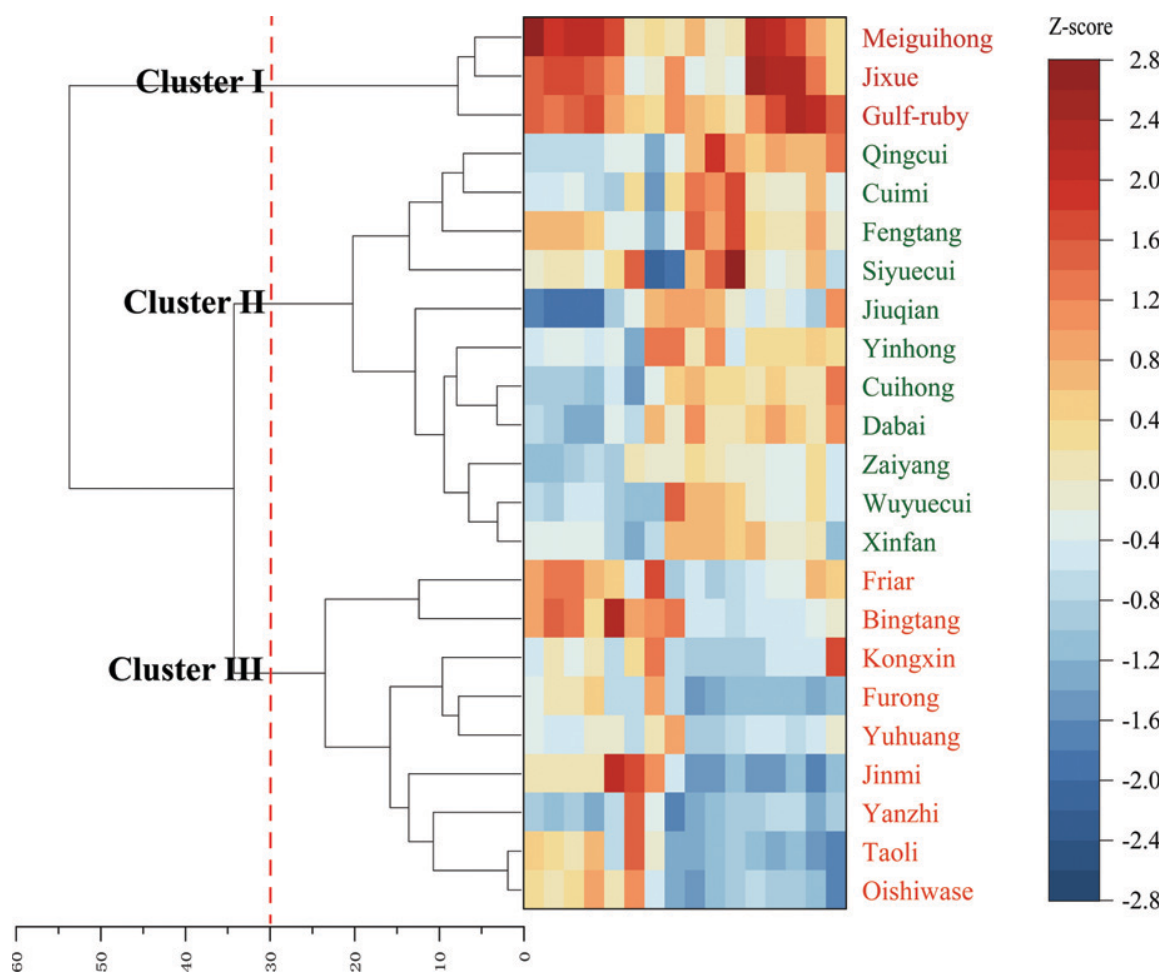

Fig. 5. Clustering diagram of different plum cultivars. The heat map was drawn after data normalization, and the average of the three measurements was normalized following the z-score model.

(Supplemental Table 2). In the PC3 dimension, toughness, TSS, and cohesiveness were mainly loaded in a positive direction. In contrast, brittleness and water content were mainly loaded in the negative direction, reflecting the toughness and inclusion of different plum cultivars (Supplemental Table 2).

According to the distribution of the cultivars in the load diagram and the principal component scores, the 23 cultivars were classified into three distinct categories (Fig. 6 and Supplemental Table 3), consistent with the cluster analysis results. The three cultivars in Cluster I were mainly distributed in the positive direction of the $\mathrm{PC} 1$ and $\mathrm{PC} 2$ dimensions, indicating that the main characteristics of fruit in this class were large size, extreme hardness, strong adhesiveness, and resistance to chewing
(Fig. 6). In Cluster I, 'Meiguihong' had the highest comprehensive score in the positive direction of the PC1 and PC2 dimensions and was the representative species in this category (Supplemental Table 3).

The 11 cultivars in Cluster II were mainly distributed in the negative direction of the PC2 and PC3 dimensions, which indicated that the main characteristics of Cluster II were small fruit size, medium hardness, and extreme brittleness (Fig. 6). In Cluster II, 'Siyuecui', 'Cuimi', and 'Qingcui' had higher comprehensive scores in the negative direction of the $\mathrm{PC} 2$ and PC3 dimensions and were representative cultivars of this class (Supplemental Table 3).

The nine cultivars in Cluster III were mainly distributed in the negative direction of $\mathrm{PC} 1$ and the positive direction of $\mathrm{PC} 2$, indicating that the main characteristics of this class were large fruit size and soft texture (Fig. 6). In Cluster III, 'Jinmi', 'Taoli', and 'Oishiwase' had higher comprehensive scores in the negative direction of PC1 and the positive direction of PC2 and were the representative cultivars of this class (Supplemental Table 3).

\section{Discussion}

The basic physicochemical properties of plum fruit contribute greatly to textural characteristics. Genetic variability is the main source of the diversity of fruit physicochemical properties (Goldenberg et al., 2015; Nardozza et al., 2011). As expected, we found significant differences in several physicochemical indexes among the 23 plum cultivars, suggesting that genetic characteristics have a decisive effect on the physicochemical properties of plum fruit. The effect of genetic characteristics is common in other horticultural species (Ayour et al., 2021; Kamal-Eldin et al., 2020). However, unexpectedly, we found certain inseparable relationships between these physicochemical properties and textural characteristics. Previous studies on textural characteristics of fruit have focused on the analysis of the texture indexes themselves (Farcuh et al., 2020; Khodabakhshian et al., 2019), and little attention has been paid to the correlation between fruit quality and textural characteristics. Nonetheless, the findings of this experiment showed that the weight, size, and inclusion conditions have certain effects on texture parameters. In previous studies, similar associations of one species at different periods or under different treatment conditions have been mentioned (Charles et al., 2018; Ornelas-Paz et al., 2018). However, such correlation among different germplasm resources in this study is unique.

Texture indicators determined by $P T$ and TPA reflect overlapping but irreplaceable information. Texture measurement system analysis has high sensitivity and objectivity and has been applied to several commercially produced fruits, including apple (Chang et al., 2018), date (Kamal-Eldin et al., 2020), and pomegranate (Fawole and Opara, 2013). In our experiment, 10 representative indicators were obtained using PT and TPA simultaneously, and the results showed varying degrees of correlation between the texture 


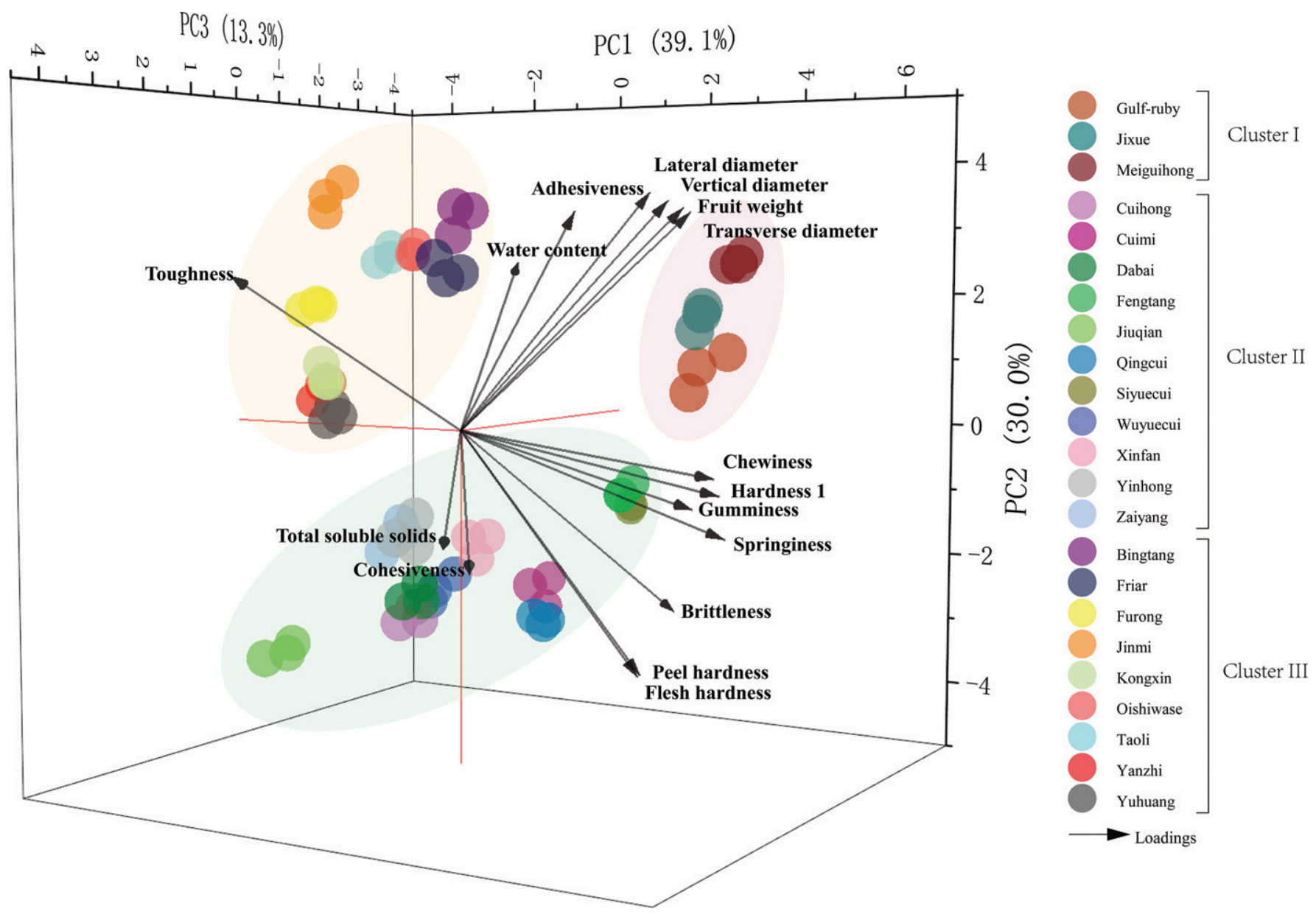

Fig. 6. Biplot graph of principal component analysis. The same round dots of the same color represent the same variety.

indicators, similar to the previous study on melon (Bianchi et al., 2016). They indicated that there was an overlapping expression of information among different texture indicators. In particular, the findings of this study validate the similarity between these two methods in determining the hardness-related characteristics of the fruit. Similar results were shown for apples (Yang et al., 2016).

Despite the aforementioned similarities, PT and TPA make unique and essential contributions to the description of plum fruit texture. For example, the measures of toughness and brittleness determined by PT cannot be achieved by TPA. Under the deformation of $50 \%, 11$ plum cultivars did not crack during TPA, and the flexibility-related indicators could not be calculated. This limitation of TPA has not been mentioned in previous studies, possibly because the texture analyzer was used on homogeneous or small stone-fruit samples (Kamal-Eldin et al., 2020; Vega-Galvez et al., 2015). In addition, the textural characteristics determined by PT and TPA correlated differently with the basic physicochemical properties. All textural characteristics determined by TPA were significantly correlated with more than one physicochemical property. The characteristics determined by PT were mostly not correlated with the physicochemical properties, and research on melon has yielded similar findings (Pan et al., 2019).
In general, PT, which is applied to parts of fruit as the test objects, can better reflect detailed characteristics of the texture traits, whereas TPA, which uses the whole fruit as the test object, and can better reflect correlation with basic physicochemical indicators.

The combined application of PCA and cluster analysis could be better used in the textural classification of plum cultivars. Cluster analysis can manage large amounts of data and observe the degree of similarity among different cultivars to achieve quality grading and characteristic classification. PCA can compress the original information through dimensionality reduction data and present the screening of effective indicators. They had been effectively applied in comprehensive quality evaluation and variety pedigree division (Bejaei et al., 2020; Huang et al., 2019). In our study, cluster analysis classified fruit texture traits according to an accurate algorithm, and 23 plum cultivars were divided into three distinct categories. This conventional clustering method was also applied on pomegranates (Hooks et al., 2021) and citrus (Wang et al., 2020). To clarify the principal components and main trait factors of each group, we integrated the clustering results into PCA for a joint analysis. In this study, PCA simplified the 16 indicators to three relatively independent dimensions. It suggested that PCA could effectively analyze the quality differences of various cultivars and the screening of characteristic trait factors, an approach already used on apricot (Ayour et al., 2021) and citrus (Goldenberg et al., 2015). In addition, unlike most studies that use cluster analysis or PCA alone (Abdul-Hamid et al., 2018; Guo et al., 2017), our comprehensive analysis also obtained characteristic traits and the representative varieties of each group by establishing a comprehensive evaluation system. The results showed that using a combination of PCA and cluster analysis, the texture quality can be more comprehensively classified and the main characteristics of plum fruit analyzed.

In summary, combining basic physicochemical index measures with PT and TPA enabled us to effectively characterize and compare the differences in fruit textural characteristics of 23 plum cultivars and to classify them into three categories: high hardness and chewiness, hard and brittle, and soft and tough. There were significant differences in the basic physicochemical properties and textural properties of the 23 plum cultivars. The physicochemical properties had significant effects on the textural characteristics, such as hardness, adhesiveness, chewiness, and cohesiveness. Our findings showed that the two detection methods, PT and TPA, reflected some similarity in providing overlapping information about plum texture traits. However, PT 
and TPA were also complementary, and there are advantages to using both methods when assessing fruit texture. In addition, we found that the combination of cluster analysis and principal component analysis could better classify the texture quality of plum fruit and extract the main features. The findings of this work are important for the scientific, accurate, and comprehensive evaluation of the quality of plum fruit and for providing a theoretical basis for the breeding of high-quality cultivars.

\section{Literature Cited}

Abdul-Hamid, N., A. Mediani, M. Maulidiani, K. Shadid, I. Ismail, F. Abas, and N. Lajis. 2018. Metabolite characterization of different palm date varieties and the correlation with their NO inhibitory activity, texture and sweetness. J. Food Sci. Technol. 55:1541-1551, doi: https:// doi.org/10.1007/s13197-018-3073-6.

Ayour, J., C.L. Bourvellec, B. Gouble, J.M. Audergon, M. Benichou, and C. Renard. 2021. Changes in cell wall neutral sugar composition related to pectinolytic enzyme activities and intraflesh textural property during ripening of ten apricot clones. Food Chem. 339:128096, doi: https:// doi.org/10.1016/j.foodchem.2020.128096.

Beaulieu, J.C., D.A. Ingram, J.M. Lea, and K.L. Bett-Garber. 2010. Effect of harvest maturity on the sensory characteristics of fresh-cut cantaloupe. J. Food Sci. 69:S250-S258.

Bejaei, M., M.A. Cliff, and A. Singh. 2020. Multiple correspondence and hierarchical cluster analyses for the profiling of fresh apple customers using data from two marketplaces. Foods 9:873, doi: https://doi.org/10.3390/foods9070873.

Bianchi, T., L. Guerrero, M. Gratacós-Cubarsí, A. Claret, J. Argyris, J. Garcia-Mas, and M. Hortós. 2016. Textural properties of different melon (Cucumis melo L.) fruit types: Sensory and physical-chemical evaluation. Scientia Hort. 201:46-56, doi: https://doi.org/10.1016/ j.scienta.2016.01.028.

Bourne, M.C. 2002. Food Texture and Viscosity: Concept and Measurement. Academic Press, San Diego, CA.

Bouzayen, M., A. Latché, P. Nath, and J.C. Pech. 2010. Mechanism of fruit ripening, p. 319-339. Plant Developmental Biology—Biotechnological Perspectives. Vol. 1. Springer, Heidelberg, Germany.

Canet, W., M.D. Alvarez, and M.J. Gil. 2007. The effect of test conditions on failure parameters during uniaxial compression of potato tissue. Intl. J. Food Sci. Technol. 42:728-738, doi: https:// doi.org/10.1111/j.1365-2621.2007.01527.x.

Causse, M., C. Friguet, C. Coiret, M. Lepicier, B. Navez, M. Lee, N. Holthuysen, F. Sinesio, E. Moneta, and S. Grandillo. 2010. Consumer preferences for fresh tomato at the European scale: A common segmentation on taste and firmness. J. Food Sci. 75:S531-S541, doi: https://doi.org/ 10.1111/j.1750-3841.2010.01841.x.

Chang, H.Y., Z.M. Vickers, and C.B.S. Tong. 2018. The use of a combination of instrumental methods to assess change in sensory crispness during storage of a "Honeycrisp" apple breeding family. J. Texture Stud. 49:228-239, doi: https://doi.org/10.1111/jtxs.12325.

Charles, M., M.L. Corollaro, L. Manfrini, I. Endrizzi, E. Aprea, A. Zanella, L. Corelli Grappadelli, and F. Gasperi. 2018. Application of a sensory-instrumental tool to study apple texture characteristics shaped by altitude and time of harvest. J. Sci. Food Agr. 98:1095-1104, doi: https://doi.org/10.1002/jsfa.8560.
Chen, H., S. Cao, X. Fang, H. Mu, H. Yang, X. Wang, Q. Xu, and H. Gao. 2015. Changes in fruit firmness, cell wall composition and cell wall degrading enzymes in postharvest blueberries during storage. Scientia Hort. 188:44-48, doi: https://doi.org/10.1016/j.scienta.2015.03.018.

Contador, L., P. Shinya, and R. Infante. 2015. Texture phenotyping in fresh fleshy fruit. Scientia Hort. 193:40-46, doi: https://doi.org/10.1016/ j.scienta.2015.06.025.

Cuevas, F.J., I. Pradas, M.J. Ruiz-Moreno, F.T. Arroyo, L.F. Perez-Romero, J.C. Montenegro, and J.M. Moreno-Rojas. 2015. Effect of organic and conventional management on bio-functional quality of thirteen plum cultivars (Prunus salicina Lindl.). PLoS One 10:e0136596, doi: https:// doi.org/10.1371/journal.pone.0136596.

Dong, W., L. Li, R. Cao, S. Xu, L. Cheng, M. Yu, Z. Lv, and G. Lu. 2020. Changes in cell wall components and polysaccharide-degrading enzymes in relation to differences in texture during sweetpotato storage root growth. J. Plant Physiol. 254:153282, doi: https://doi.org/10.1016/j.jplph. 2020.153282.

Famiani, F., V. Casulli, A. Baldicchi, A. Battistelli, S. Moscatello, and R.P. Walker. 2012. Development and metabolism of the fruit and seed of the Japanese plum Ozark premier (Rosaceae). J. Plant Physiol. 169:551-560, doi: https:// doi.org/10.1016/j.jplph.2011.11.020.

Food and Agricultural Organization. 2020, 12 Dec. 5 Feb. 2021. <http://www.fao.org/faostat/zh/ ?\#data/QC $>$.

Farcuh, M., B. Copes, G. Le-Navenec, J. Marroquin, T. Jaunet, C. Chi-Ham, D. Cantu, K.J. Bradford, and A. Van Deynze. 2020. Texture diversity in melon (Cucumis melo L.): Sensory and physical assessments. Postharvest Biol. Technol. 159:111 024, doi: https://doi.org/10.1016/j.postharvbio. 2019.111024.

Farcuh, M., R.M. Rivero, A. Sadka, and E. Blumwald. 2018. Ethylene regulation of sugar metabolism in climacteric and non-climacteric plums. Postharvest Biol. Technol. 139:20-30, doi: https://doi.org/ 10.1016/j.postharvbio.2018.01.012.

Fawole, O.A. and U.L. Opara. 2013. Harvest discrimination of pomegranate fruit: Postharvest quality changes and relationships between instrumental and sensory attributes during shelf life. J. Food Sci. 78:1264, doi: https://doi.org/ 10.1111/1750-3841.12176

Ghnimi, S., M. Al-Shibli, H.R. Al-Yammahi, A Al-Dhaheri, and A. Kamal-Eldin. 2018. Reducing sugars, organic acids, size, color, and texture of 21 Emirati date fruit varieties (Phoenix dactylifera, L.). NFS J. 12:381, doi: https:// doi.org/10.1016/j.nfs.2018.04.002.

Goldenberg, L., Y. Yaniv, T. Kaplunov, A. Doron-Faigenboim, N. Carmi, and R. Porat. 2015. Diversity in sensory quality and determining factors influencing mandarin flavor liking. J. Food Sci. 80:418, doi: https://doi.org/10.1111/1750-3841.12742.

Guo, X., J. Xu, X. Cui, H. Chen, and H. Qi. 2017. iTRAQ-based protein profiling and fruit quality changes at different development stages of oriental melon. BMC Plant Biol. 17:28, doi: https://doi.org/10.1186/s12870-017-0977-7.

Harker, F.R., J. Maindonald, S.H. Murray, F.A. Gunson, I.C. Hallett, and S.B. Walker. 2002. Sensory interpretation of instrumental measurements 1: Texture of apple fruit. Postharvest Biol. Technol. 24:225-239, doi: https://doi.org/ 10.1016/S0925-5214(01)00158-2.

Hooks, T., G. Niu, J. Masabni, Y. Sun, and G. Ganjegunte. 2021. Performance and phytochemical content of 22 pomegranate (Punica granatum) varieties. HortScience 56:217, doi: https:// doi.org/10.21273/hortsci15551-20.
Huang, S.J., X.Y. Liu, B. Xiong, X. Qiu, G.C. Sun, X.J. Wang, X. Zhang, Z.X. Dong, and Z.H. Wang. 2019. Variation in limonin and nomilin content in citrus fruits of eight varieties determined by modified HPLC. Food Sci. Biotechnol. 28:641-647, doi: https://doi.org/10.1007/s10068-018-0509-8.

Jiang, C.C., Z.Z. Fang, D.R. Zhou, S.L. Pan, and X.F. Ye. 2019. Changes in secondary metabolites, organic acids and soluble sugars during the development of plum fruit cv. 'Furongli' (Prunus salicina Lindl). J. Sci. Food Agr. 99:1010-1019, doi: https://doi.org/10.1002/jsfa.9265.

Jubb, K.V.F. 1982. Food Texture and Viscosity. Academic Press, San Diego, CA.

Kamal-Eldin, A., N. George, B. Sobti, N. AlRashidi, S. Ghnimi, A. Ali, A. Andersson, R. Andersson, A. Antony, and F. Hamed. 2020. Dietary fiber components, microstructure, and texture of date fruits (Phoenix dactylifera, L.). SCI REP-UK 10:21767, doi: https://doi.org/10.1038/ s41598-020-78713-4.

Khodabakhshian, R., B. Emadi, M. Khojastehpour, and M.R. Golzarian. 2019. Instrumental measurement of pomegranate texture during four maturity stages. J. Texture Stud. 50:410-415, doi: https://doi.org/10.1111/jtxs.12406.

Kim, D.O., O.K. Chun, Y.J. Kim, H.Y. Moon, and C.Y. Lee. 2003. Quantification of polyphenolics and their antioxidant capacity in fresh plums. J. Agr. Food Chem. 51:6509-6515, doi: https://doi.org/10.1021/jf0343074.

Li, P., W. Wu, F. Chen, X. Liu, and J. Chen. 2015. Prunus salicina 'Crown', a Yellow-fruited Chinese Plum. HortScience 50:1822-1824, doi: https://doi.org/10.21273/HORTSCI.50.12.1822.

Liaudanskas, M., R. Okulevičiūte, J. Lanauskas, D. Kviklys, K. Zymone, T. Rendyuk, V. Žvikas, N. Uselis, and V. Janulis. 2020. Variability in the content of phenolic compounds in plum fruit. Plants 9:1611, doi: https://doi.org/ $10.3390 /$ plants9111611.

Nardozza, S., J. Gamble, L.G. Axten, M.W. Wohlers, M.J. Clearwater, J. Feng, and F.R. Harker. 2011. Dry matter content and fruit size affect flavour and texture of novel Actinidia deliciosa genotypes. J. Sci. Food Agr. 91:742-748, doi: https://doi.org/10.1002/jsfa.4245.

Nybom, H., M. Ahmadi-Afzadi, K. Rumpunen, and I. Tahir. 2020. Review of the impact of apple fruit ripening, texture and chemical contents on genetically determined susceptibility to storage rots. Plants 9:831, doi: https://doi.org/ 10.3390/plants9070831.

Ornelas-Paz, J.J., B.M. Quintana-Gallegos, P. Escalante-Minakata, J. Reyes-Hernandez, J.D. Perez-Martinez, C. Rios-Velasco, and S. RuizCruz. 2018. Relationship between the firmness of Golden Delicious apples and the physicochemical characteristics of the fruits and their pectin during development and ripening. J. Food Sci. Technol. 55:33-41, doi: https://doi.org/10.1007/ s13197-017-2758-6.

Pan, H., D. Liu, Q. Shao, G. Gao, and H. Qi. 2019. Analysis and comprehensive evaluation on textual quality of different varieties of oriental melon fruit at ripening stage. J. Fruit Sci. 40:35-42, doi: https://doi.org/10.7506/spkx10 02-6630-20181025-299.

Rana, S., R. Pradhan, and S. Mishra. 2018. Variation in properties of tender jackfruit during different stages of maturity. J. Food Sci. Technol. 55:2122-2129, doi: https://doi.org/10.1007/s131 97-018-3127-9.

Schmitz, C., M. Clark, J.J. Luby, J. Bradeen, Y. Guan, K. Evans, B. Orcheski, S. Brown, S. Verma, and C. Peace. 2013. Fruit texture phenotypes of the RosBREED U.S. apple reference 
germplasm set. HortScience 48:296-303, doi: https://doi.org/10.21273/HORTSCI.48.3.296.

Stacewicz-Sapuntzakis, M., P.E. Bowen, E.A. Hussain, B.I. Damayanti-Wood, and N.R. Farnsworth. 2001. Chemical composition and potential health effects of prunes: A functional food? Critical Rev. Food Technol. 41:251-286, doi: https://doi.org/10.1080/20014091091814.

Szczesniak, A.S. 2010. Classification of textural characteristics. J. Food Sci. 28:385-389, doi: https:// doi.org/10.1111/j.1365-2621.1963.tb00215.x.

Usenik, V., D. Kastelec, R. Veberič, and F. Stampar. 2008. Quality changes during ripening of plums (Prunus domestica L.). Food Chem. 111: 830-836, doi: https://doi.org/10.1016/j.foodchem. 2008.04.057.

Vega-Galvez, A., L. Zura-Bravo, R. Lemus-Mondaca, J. Martinez-Monzo, I. Quispe-Fuentes, L. Puente, and K. Di Scala. 2015. Influence of drying temperature on dietary fibre, rehydration properties, texture and microstructure of Cape gooseberry (Physalis peruviana L.). J. Food Sci. Technol. 52:2304-2311, doi: https://doi. org/10.1007/s13197-013-1235-0.

Vigneau, E., M. Charles, and M. Chen. 2014. External preference segmentation with additional information on consumers: A case study on apples. Food Qual. Prefer. 32:83-92.

Vlaic, R., V. Muresan, A. Muresan, C. Muresan, A. Paucean, V. Mitre, S. Chis, and S. Muste. 2018. The changes of polyphenols, flavonoids, anthocyanins and chlorophyll content in plum peels during growth phases: from fructification to ripening. Not. Bot. Horti Agrobot. Cluj-Napoca 46:148-155, doi: https://doi.org/10.15835/ nbha46111017.

Wang, F., Y. Huang, W. Wu, C. Zhu, R. Zhang, J. Chen, and J. Zeng. 2020. Metabolomics analysis of the peels of different colored citrus fruits (Citrus reticulata $\mathrm{cv}$. 'Shatangju') during the maturation period based on UHPLC-QQQ-MS. Molecules 25, doi: https://doi.org/10.3390/ molecules25020396.

Wong, R., S. Kim, S.J. Chung, and M.S. Cho. 2020. Texture preferences of Chinese, Korean and US consumers: a case study with apple and pear dried fruits. Foods 9:377, doi: https:// doi.org/10.3390/foods9030377.

Yang, L., P. Cong, Q. Wang, and G. Kang. 2016. Texture changes of different apple varieties during storage. J. Fruit Sci. 33:1439-1446, doi: https://doi.org/10.13925/j.cnki.gsxb.20160146.

Zhang, J. and E. Zhou. 1998. Plum. Annals of Chinese fruit trees. China Forestry Press, Beijing.

Zhou, J., Y. Bo, X. Xie, R. Bai, J. Liang, M. Yang, Y. Han, and R. Sun. 2020. Optimization of texture measurement parameters and characteristics analysis of fig fruit. Non-wood For. Res. 38:258-264, doi: https://doi.org/10.14067/ j.cnki.1003-8981.2020.03.030. 
Supplemental Table 1. Distribution of physicochemical indexes and texture indexes of plum fruit in different groups. The cell with the highest average value in each row is highlighted.

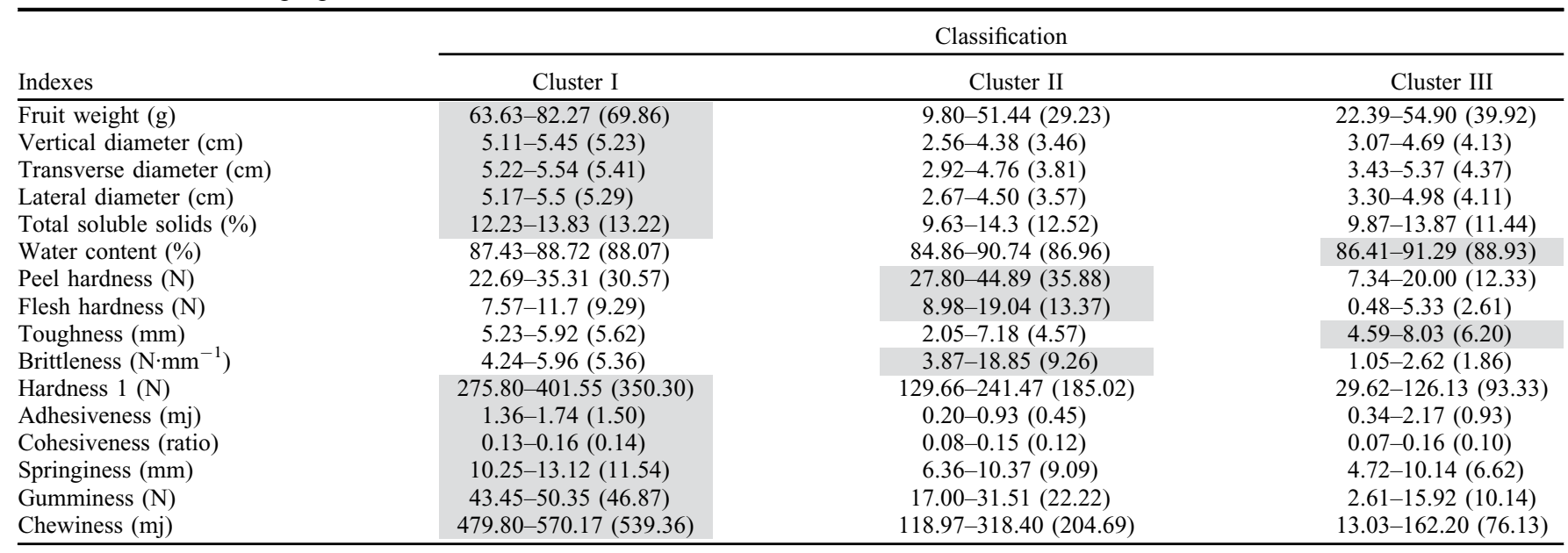

Supplemental Table 2. The eigenvectors of the first three principal component axes in principal component analysis. The top five indicators with absolute scores on each principal component are highlighted.

\begin{tabular}{lrrr}
\hline & & Principal component \\
\cline { 2 - 4 } Indexes & PC1 & \multicolumn{1}{c}{ PC2 } & PC3 \\
\hline Chewiness & 0.922 & -0.013 & -0.032 \\
Gumminess & 0.918 & 0.121 & 0.183 \\
Springiness & 0.908 & 0.171 & 0.138 \\
Hardness 1 & 0.907 & -186 & 0.015 \\
Peel hardness & 0.774 & -0.476 & -0.164 \\
Flesh hardness & 0.705 & -0.535 & -0.297 \\
Cohesiveness & 0.554 & -0.225 & 0.546 \\
Brittleness & 0.548 & -0.42 & -0.657 \\
Total soluble solids & 0.483 & -0.132 & 0.557 \\
Fruit weight & 0.359 & 0.904 & -0.127 \\
Transverse diameter & 0.283 & 0.912 & -0.158 \\
Vertical diameter & 0.281 & 0.919 & -0.093 \\
Lateral diameter & 0.112 & 0.9 & -0.179 \\
Adhesiveness & 0.049 & 0.769 & 0.031 \\
Toughness & -0.262 & 0.356 & 0.811 \\
Water content & -0.405 & 0.356 & -0.482 \\
\hline
\end{tabular}


Supplemental Table 3. Principal component value and comprehensive evaluation of different plum varieties. Comprehensive score of Cluster I $=$ PC1 + PC2; comprehensive score of Cluster II $=(-\mathrm{PC} 2)+(-\mathrm{PC} 3)$; comprehensive score of Cluster II $=(-\mathrm{PC} 1)+\mathrm{PC} 2$. The top third of the cells in each cluster is highlighted.

\begin{tabular}{|c|c|c|c|c|c|c|}
\hline \multirow[b]{2}{*}{ Cultivars } & \multicolumn{3}{|c|}{ Value of principal components } & \multicolumn{3}{|c|}{ Comprehensive score of cluster } \\
\hline & $\mathrm{PC} 1$ & PC2 & $\mathrm{PC} 3$ & Cluster I & Cluster II & Cluster III \\
\hline Meiguihong & 5.25 & 2.51 & -0.27 & 7.76 & - & - \\
\hline Jixue & 5.13 & 1.76 & 0.61 & 6.88 & - & - \\
\hline Gulf-ruby & 5.15 & 1.03 & 0.50 & 6.19 & - & - \\
\hline Siyuecui & 0.47 & -1.55 & -4.22 & - & 5.77 & - \\
\hline Cuimi & 0.31 & -2.61 & -1.77 & - & 4.38 & - \\
\hline Qingcui & 1.26 & -2.82 & -0.54 & - & 3.36 & - \\
\hline Fengtang & 1.89 & -1.01 & -2.02 & - & 3.03 & - \\
\hline Wuyuecui & -0.36 & -2.36 & 0.11 & - & 2.25 & - \\
\hline Xinfan & 0.15 & -1.71 & -0.24 & - & 1.95 & - \\
\hline Zaiyang & -1.37 & -1.62 & 0.05 & - & 1.58 & - \\
\hline Cuihong & 0.02 & -2.58 & 1.24 & - & 1.34 & - \\
\hline Jiuqian & -2.12 & -3.14 & 1.90 & - & 1.24 & - \\
\hline Dabai & 0.20 & -2.24 & 1.36 & - & 0.88 & - \\
\hline Yinhong & 0.57 & -1.27 & 1.92 & - & -0.65 & - \\
\hline Jinmi & -2.89 & 3.47 & -0.07 & - & - & 6.35 \\
\hline Taoli & -2.89 & 2.57 & -1.42 & - & - & 5.46 \\
\hline Oishiwase & -2.28 & 2.64 & -1.44 & - & - & 4.92 \\
\hline Furong & -2.70 & 1.82 & 0.56 & - & - & 4.53 \\
\hline Yanzhi & -3.73 & 0.47 & -0.69 & - & - & 4.20 \\
\hline Bingtang & 0.57 & 3.12 & 0.70 & - & - & 2.55 \\
\hline Kongxin & -1.55 & 0.85 & 1.49 & - & - & 2.41 \\
\hline Yuhuang & -1.62 & 0.28 & 1.25 & - & - & 1.89 \\
\hline Friar & 0.57 & 2.38 & 1.00 & - & - & 1.81 \\
\hline
\end{tabular}

